\title{
RELATO DE EXPERIÊNCIAS PEDAGÓGICAS DE ENSINO E APRENDIZAGEM NA MODALIDADE DE EDUCAÇÃO A DISTÂNCIA NO CURSO DE LICENCIATURA EM LETRAS ESPANHOL DO IFRN
}

\author{
F. C. DE SENA \\ Instituto Federal de Educação, Ciência e Tecnologia do Rio Grande do Norte \\ senaprofessor@hotmail.com
}

Artigo submetido em junho/2012 e aceito em dezembro/2012

DOI: 10.15628/rbept.2012.3121

\section{RESUMO}

O presente artigo tem por objetivo apresentar algumas experiências de ensino e aprendizagem vivenciadas em uma turma do 5 o período do Curso de Licenciatura em Letras Espanhol na modalidade de educação a distância, do Instituto Federal de Educação, Ciência e Tecnologia do Rio Grande do Norte - Campus Central, na disciplina Organização e Gestão da Educação Brasileira. Para tanto, propõe-se analisar tais experiências enfatizando os pontos positivos e negativos do processo pedagógico ora realizado, elencando todos os percursos formativos os quais os educandos, professores e tutores foram submetidos no desenrolar da disciplina citada acima. A perspectiva é a de entender as dificuldades, desafios e possíveis rumos a serem traçados na EaD no curso de Licenciatura em Letras Espanhol do IFRN.

PALAVRAS-CHAVE: Experiências de ensino e aprendizagem, educação a distância, organização e gestão da educação brasileira, percursos formativos.

\section{EDUCATIONAL EXPERIENCES IN TEACHING MODE OF DISTANCE EDUCATION COURSE OF BACHELOR IN SPANISH LYRICS IFRN}

\begin{abstract}
This paper aims to present some experiences of teaching and experienced learning in a class of 5 th period Bachelor of Arts Spanish in the form of distance education, the Federal Institute of Education, Science and Technology of Rio Grande do Norte - Campus Central, discipline Organization and Management of the Brazilian Education. For this purpose, it is proposed to analyze such experiences emphasizing the positive and negative points
\end{abstract}

of the pedagogical process now performed, listing all training courses which the students, teachers and tutors were submitted in the course of discipline mentioned above. The perspective is to understand the difficulties, challenges and possible directions are plotted in distance education in the Bachelor's Degree in Arts from the Spanish IFRN.

KEYWORDS: Experiences of teaching and learning, distance education, Organization and Management of the Brazilian Education. 


\section{INTRODUÇÃO}

A modalidade de educação a distância $(E a D)$ não é algo recente, pois desde muito tempo atrás já havia cursos por correspondência, utilizando-se para isso as cartas como meio de comunicação entre os mestres e os alunos. Essa forma de ensino era profissional pois as pessoas buscavam qualificação e/ou formação profissional, sem muita preocupação com a educação formal. No Brasil, as primeiras experiências remontam ao fim da década de 1930 e início da década de 1940, seguindo-se pelas décadas de 1960-70 através de cursos ofertados via rádio ou televisão (HERMIDA; BONFIM, 2006). No entanto, foi a partir de 1996 com a promulgação da Lei $n^{\circ} 9.394-$ Lei de Diretrizes e Bases da Educação (LDB) (BRASIL, 1996), principalmente com a redação do artigo 80 da referida Lei, que a Educação a distância passou a ser realmente implementada, expandindo a oferta de cursos para todos os níveis e modalidades de ensino, e de educação continuada. Em 2004, foi editada a Portaria $n^{\circ}$ 4059/2004 (BRASIL, 2004) que preconiza a oferta a distância de cursos superiores e prevê a inserção curricular de disciplinas utilizando a modalidade semipresencial, desde que não ultrapassem 20\% da carga horária total dos cursos. Em 19 de dezembro de 2005, foi publicado o Decreto 5.622 (BRASIL, 2005), o qual veio regulamentar de fato o artigo 80 da LDB, pois no artigo $2 \circ$ deste Decreto se encontra a forma como a oferta de educação a distância deve ser organizada, nos seguintes níveis e modalidades:

I. educação básica, nos termos do art. 30 do referido Decreto;

II. educação de jovens e adultos, nos termos do art. 37 da Lei no 9.394, de 20 de dezembro de 1996;

III. educação especial, respeitadas as especificidades legais pertinentes;

IV. educação profissional, abrangendo os seguintes cursos e programas:

a) técnicos, de nível médio; e

b) tecnológicos, de nível superior;

V. educação superior, abrangendo os seguintes cursos e programas:

a) sequenciais;

b) de graduação;

c) de especialização;

d) de mestrado; e

e) de doutorado. (BRASIL, 2005).

Sendo assim, o Decreto $n^{\circ} 5.622 / 2005$ trouxe avanços significativos para a educação a distância, equiparando-a à educação presencial. Outro passo importante foi dado com a promulgação do Decreto 5.800, de 08 de julho de 2006 (BRASIL, 2006), o qual criou a Universidade Aberta do Brasil (UAB), que se constitui como um conjunto de instituições de nível superior integradas para oferecer às camadas da população que tem dificuldades ao acesso universitário, a formação necessária, priorizando-se, no entanto, o atendimento aos professores que atuam na educação básica, além de dirigentes, gestores e trabalhadores em educação dos Estados, Municípios e do Distrito Federal.

Nesse sentido, o Instituto Federal de Educação, Ciência e Tecnologia do Rio Grande do Norte (IFRN) implementou ações significativas no intuito de estabelecer um Campus que ofertasse a educação na modalidade a distância. Dessa forma, segundo informações do Portal do IFRN, em janeiro de 2011, foi criado o Campus de Educação a Distância do referido Instituto, "credenciado 
pela Portaria № 1.369 de 7 de dezembro de 2010 e tem o seu regimento e estrutura aprovados pela Resolução 15/2010 CONSUP/IFRN, 29/10/2010 e pela Resolução 16/2010 CONSUP/IFRN, 01/03/2012", e sua estrutura física localiza-se nas dependências do Campus Natal-Central (IFRN, 2011).

São oferecidos no Campus EaD, cursos técnicos de nível médio subseqüente, de graduação e de especialização, além dos cursos de aperfeiçoamento, ofertados todos na modalidade de educação a distância. As aulas são realizadas através de uma área virtual de aprendizagem, denominada de Plataforma Moodle, em que cada aluno utiliza login e senha pessoais e dispõem de acesso a recursos multimídia, ferramentas e dispositivos diversificados, mediados pelo uso das Novas Tecnologias da Informação e Comunicação (NTIC).

Dessa forma, objetiva-se com esse relato de experiência, elencar às diversas atividades pedagógicas desenvolvidas em uma turma do 5 o período na modalidade EaD, na disciplina Organização e Gestão da Educação Brasileira, do Curso de Licenciatura em Letras Espanhol do IFRN - Campus Central, expondo com detalhes os primeiros contatos com a turma, o quantitativo de alunos matriculados, o desenvolvimento das aulas, os feedbacks, os recursos pedagógicos utilizados, os instrumentos avaliativos empregados, até o resultado final.

Entende-se que, as informações contidas neste artigo são extremamente relevantes ao contexto pedagógico, cientifico e tecnológico, tendo em vista a presente expansão de cursos ofertados através da modalidade de educação a distância, com um contingente significativo de professores, tutores e alunos envolvidos nessa "teia" de saberes, a qual visa uma educação de qualidade para todos.

Espera-se que os resultados obtidos nesta pesquisa sirvam de norteadores aos gestores, professores e tutores que atuam na EaD, a fim de que sejam criadas novas estratégias de ensino que venham favorecer a produção de conhecimentos por parte dos discentes e de todos aqueles que trabalham nessa modalidade de educação.

\section{REVISÃO BIBLIOGRÁFICA}

Com o advento da internet e das Novas Tecnologias da Informação e da Comunicação (NTIC), tornou-se possível a oferta de cursos à distância utilizando para isso, os recursos midiáticos. Essa forma de conceber a educação veio modificar as estruturas sociais e educativas concernentes ao ensinar e aprender, utilizando-se como elemento mediador, um Ambiente Virtual de Aprendizagem onde são realizadas atividades com vistas à produção do conhecimento. Nesse sentido, Kenski (2008, p. 13) enfatiza que

Com um grau maior de complexidade nas formas sociais de interação e comunicação no ensino, nós podemos usar o espaço virtual para realizar atividades - didaticamente ativas e envolventes - construídas com a participação e a cooperação entre alunos e professores. Um ensino baseado em trocas e desafios. Que envolva e motive os alunos para a participação e a expressão de suas opiniões.

1. Dentre os cursos de graduação ofertados no Campus EaD do IFRN, está o de Licenciatura em Letras Espanhol, que de acordo com o Projeto Pedagógico do Curso Superior de Licenciatura em Letras Espanhol na modalidade de educação a distância (IFRN, 2012, p. 14), tem como 
objetivo geral,

formar professores licenciados em Língua Espanhola / Espanhol para a Educação Básica com visão ampla do papel do educador, capazes de trabalhar em equipes multidisciplinares e interdisciplinares e utilizar os conhecimentos linguísticos para a compreensão do mundo que o cerca e para a resolução de problemas do seu cotidiano de vida e do mundo do trabalho.

A proposta pedagógica do curso possibilita integrar conhecimentos pedagógicos e específicos, proporcionando o diálogo entre as várias visões de mundo e "está organizada por núcleos articuladores de saberes, os quais favorecem a prática da interdisciplinaridade e da contextualização" (IFRN, PPC, 2012, p.17). Esses núcleos estão estruturados sob as seguintes concepções: Núcleo Fundamental, Núcleo Didático-Pedagógico, Núcleo Epistemológico, Núcleo Específico.

A carga horária total do curso é de 3.704 horas, distribuídas da seguinte forma: "2.520 horas destinadas à formação docente (considerando que são 2.220 horas de disciplinas obrigatórias e o mínimo de 300 horas de disciplinas eletivas), 184 horas de atividades complementares e 1.000 horas à prática profissional". (IFRN, PPC, 2012, p.19).

Como ferramenta pedagógica para a realização de atividades a distância, o IFRN utiliza o Moodle, o qual se constitui em um sistema computacional que dá suporte às atividades de ensino e aprendizagem na Educação a Distância, permitindo articular palavras, sons e imagens. Os recursos nele disponibilizados (relatórios, fóruns, chats, envio de arquivos entre outros), favorecem e permitem o acompanhamento do desenvolvimento da aprendizagem do aluno, oferecendo insumos às análises do processo de avaliação, além de possibilidades ao docente para observar como a aprendizagem se processa. De acordo com o Projeto Pedagógico do Curso Superior de Licenciatura em Letras Espanhol na modalidade a distância (2012, p.40):

dentre os meios e recursos disponíveis na plataforma de aprendizagem (Moodle), utiliza-se basicamente de: suporte informático - sistemas multimeios (CD-ROM), webconferência e Internet; espaços de comunicação virtual tais como chats, grupos de discussão, correio eletrônico, entre outros; materiais audiovisuais gravações de áudio, de vídeo, transmissões de programas televisivos; materiais em meio eletrônico - guias de estudos, cadernos de exercícios, unidades didáticas, textos, livros, entre outros; e softwares produzidos especificamente para o desenvolvimento das quatro habilidades (ouvir, falar, ler e escrever).

Nesse sentido, as novas tecnologias podem ajudar de maneira significativa no processo afetivo entre professores e alunos, mediados pela interação proporcionada pelos recursos tecnológicos, principalmente aqueles oriundos da internet (chat, redes sociais, ambiente virtual de aprendizagem (AVA) etc.), gerando relações que envolvam respeito, confiança e cooperação. Por isso Kenski (2012, p. 102) enfatiza que "além disso, nos ambientes virtuais de aprendizagem, o professor dedica-se a um processo intensivo de interação com cada um dos alunos (o que é impossível nos ambientes presenciais) e o estimula a comunicar-se (principalmente por escrito)."

Outro ponto importantíssimo em um curso seja presencial ou a distância é a forma como a avaliação é conduzida, sendo um requisito necessário ao bom funcionamento de toda prática educativa. Esse processo inicia-se na fase de planejamento, quando há o delineamento dos 
objetivos, a seleção dos conteúdos, os métodos adequados, os recursos didáticos utilizados, até o processo de avaliação. Por isso, para Vasconcelos (2006, p. 175), a avaliação

é um recurso muito importante para a gestão da sala de aula, uma vez que permite localizar as necessidades e dirigir a ação no sentido de sua superação; poderíamos dizer mesmo que sem a avaliação a gestão da atividade pedagógica ficaria inviabilizada, já que faltariam os elementos críticos para a tomada de decisão.

Todavia, para que aconteça um processo avaliativo eficaz da aprendizagem escolar, faz-se necessário ter em mente que o professor precisa criar estratégias que venham favorecer o desenvolvimento do educando como um todo e que na hora de avaliar enxergue-se todo o contexto no qual o aluno está inserido, e assim, chegue-se a patamares mais elevados de conhecimentos.

Outro ponto importante na hora de avaliar é a clareza daquilo que é solicitado aos alunos, pois, muitas vezes, os educandos não conseguem se sobressair bem nas avaliações, não por desconhecimento do que se é pedido, mas devido a falta de entendimento das questões, algumas vezes permeadas por ambiguidades e incoerências. Luckesi $(1998$, p. 38) enfatiza o seguinte:

A ambigüidade do que se solicita num teste pode revelar mal a expectativa do professor e, deste modo, a resposta do aluno poderá ser considerada inadequada, por não estar aparentemente capacitado para ela. No entanto, o aluno poderia estar capacitado e só não manifestou o desempenho esperado por ter sido impossível entender o que se queria.

Nesse sentido, para que o professor tenha condições de avaliar satisfatoriamente seus alunos faz-se necessário que ele se aproprie dos diversos instrumentos de avaliação, os quais visam diagnosticar e superar dificuldades encontradas durante todo o processo, como também corrigir falhas e instigar os educandos a continuarem estudando. Tais procedimentos têm que ser aplicados continuamente, ou seja, no início, durante e no final de cada unidade didática ou bimestre. Para Libâneo (1994, p. 205), “[...] o processo de avaliação assume várias formas, umas mais sistemática, outras menos, umas formais, outras mais informais".

Essa diversificação é imprescindível, pois só assim haverá condições do professor avaliar muitos conhecimentos e competências que geralmente ficam de fora quando se utiliza apenas os procedimentos avaliativos costumeiros, que não dão ênfase ao vasto conjunto de práticas e saberes significativos que estão intrinsecamente atrelados ao processo de ensino e aprendizagem. Para Cordeiro (2009, p.160), "[...] é preciso caminhar na direção de procedimentos avaliativos cada vez mais diferenciados e individualizados ou que pelo menos permitam a manifestação das reais aprendizagens e dificuldades obtidas por cada um dos alunos".

Quando a avaliação é bem compreendida pelo professor nos seus aspectos conceituais e funcionais, o processo ocorrerá mais espontaneamente e os alunos não terão a avaliação como um - bicho de sete cabeças, mas se sentirão valorizados à medida que o docente passa a utilizar o instrumento certo, estimulando assim, o educando a continuar estudando. Conforme frisa Libâneo (1994, p. 205),

[...] O professor que compreendeu o conceito e as funções da avaliação concluirá que, se o processo de ensino for bem conduzido, as provas parciais ou finais serão 
apenas o reflexo do seu trabalho. Ou seja, os alunos quase sempre terão bons resultados e isto os estimulará ainda mais para o estudo.

É nesse ponto, que entra em cena o importante papel do professor nessa sociedade digital, o qual "[...] é recuperar a origem e a memória do saber, de estabelecer uma certa ordem e direcionamento para as práticas, os conhecimentos, as vivências e posicionamentos apreendidos nos mais variados ambientes e equipamentos: dos livros aos computadores, redes e ambientes virtuais" (KENSKI, 2012 p. 99). Ainda conforme a mesma autora, Kenski (2012), o professor precisa atuar junto a seus alunos nos mais diferentes espaços, seja em sala de aula ou mesmo no ensino a distância, dinamizando a ação didática, orientando, ordenando e organizando as diversas atividades didáticas, proporcionando aos alunos desenvolverem o pensamento crítico e reflexivo dos dados coletados, transformando-os em informações pertinentes ao saber educacional.

\section{METODOLOGIA}

O contato virtual entre alunos e professor/tutores, deu-se através da Plataforma Moodle (Ambiente Virtual utilizado no IFRN), onde todas as atividades a distância são planejadas e desenvolvidas virtualmente. Por meio de abas, cada página foi construída seguindo uma sequência lógica, em que partiu-se de uma página inicial, contendo a apresentação da disciplina Organização e Gestão da Educação Brasileira, um texto de umas boas-vindas aos educandos e alguns esclarecimentos iniciais, como por exemplo, o calendário de atividades da disciplina, além de orientações quanto à forma de avaliação e o quantitativo de aulas que iriam ser ministradas. Além disso, foi disponibilizado um fórum de noticias contendo a apresentação do professor da disciplina e tutoras; fórum esse que serviu durante toda a ministração das aulas, como local destinado a informações gerais da disciplina. As aulas foram dispostas na Plataforma em cinco módulos; cada um contendo três aulas, totalizando assim, quinze aulas ministradas.

Os elementos visuais presentes em cada página eram constituídos de uma imagem inicial, representando em geral a temática abordada no módulo, seguidos dos temas das aulas e seus respectivos objetivos. Logo abaixo, era aberto um fórum de dúvidas, para que os alunos fossem postando seus questionamentos e os conteúdos das aulas em formato de arquivos PDF para que os alunos pudessem baixá-los para o computador. O último elemento da página, geralmente era composto por uma atividade avaliativa, com prazo e nota determinados.

\section{RESULTADOS E DISCUSSÕES}

A disciplina Organização e Gestão da Educação Brasileira foi ofertada a uma turma de 141 educandos matriculados, distribuídos em sete polos de apoio presenciais nas seguintes cidades: Caraúbas, Currais Novos, Grossos, Marcelino Vieira, Natal, Parnamirim e São Gonçalo do Amarante. O Quadro 01 - a seguir, mostra cada polo de apoio presencial e seus respectivos quantitativos de alunos.

Para o início das atividades, foi pedido aos alunos que lessem os conteúdos da aula 01, os quais tratavam sobre o conceito de educação sob uma perspectiva histórico-filosófica, juntamente com um vídeo disponibilizado através de um link que era visualizado via youtube. Após o período proposto, foi aberto um fórum de participação da referida aula, a fim de que os alunos respondessem ao seguinte questionamento: "Com base nos conteúdos que você leu na Aula 01, 
reflita sobre os processos educativos dos quais teve experiência até hoje, sobre o seu ambiente social e cultural e, com base nesses elementos, defina o que é para você, hoje, a educação. Será que, realmente, ninguém escapa da educação? Justifique". Houve uma participação de 45 alunos, equivalendo a $31,9 \%$ do total de matrículas da turma. Quanto às respostas ao questionamento propostos, percebeu-se que $78 \%$ dos educandos teceram comentários curtos/superficiais, enquanto $22 \%$, procuraram embasar melhor as respostas, posicionando-se com mais segurança em relação ao tema.

Quadro 1: Polos de apoio presenciais e seus respectivos quantitativos de alunos

\begin{tabular}{|c|c|}
\hline POLO DE APOIO PRESENCIAL & QUANTITATIVO DE ALUNOS \\
\hline Caraúbas & 28 \\
\hline Currais Novos & 16 \\
\hline Grossos & 18 \\
\hline Marcelino Vieira & 23 \\
\hline Natal & 22 \\
\hline Parnamirim & 26 \\
\hline São Gonçalo do Amarante & 08 \\
\hline TOTAL & 141 \\
\hline
\end{tabular}

Fonte: Elaboração do autor, a partir de informações de: http://ead.ifrn.edu.br/moodle

Dessa forma, durante as aulas ministradas a distância, procurou-se diversificar os instrumentos avaliativos, com a finalidade de se atingir os objetivos propostos em cada aula. Por isso, a primeira atividade avaliativa constando nota, deu-se envolvendo os conteúdos das aulas 02 e 03, abordando as temáticas sobre as concepções pedagógicas na história ocidental (aula 02) e o período do positivismo até ao pensamento pedagógico crítico do século XX (aula 03). Foi solicitado aos educandos, que elaborassem um texto dissertativo, enfocando a importância que o estudo das ideias pedagógicas tem para as práticas educativas. Como orientações básicas, pediu-se que ao longo do texto, eles fossem citando as ideias de alguns pensadores estudados nessas aulas e que se posicionassem a respeito de cada ideia. Para a postagem da atividade avaliativa, foi utilizado, já que se trata de um modo de envio de arquivos que permite feedbacks e reenvios de arquivos para serem feitas modificações. Essa avaliação foi realizada em dupla e teve uma adesão de 73 alunos.

Dando início ao Módulo II, abordou-se os conteúdos das aulas 03, 04, 05 que traziam como temas: a conquista da educação como um direito social e as políticas públicas; a redemocratização do país e a democratização da educação e a reordenação da Educação Nacional: Constituição Federal, Lei de Diretrizes e Bases da educação Nacional, Plano Nacional de Educação e outras leis. Para a avaliação dessas aulas, foi solicitando a elaboração de um quadro, destacando a evolução histórica das conquistas educacionais brasileiras, enfocando como se deu a participação da sociedade civil nos processos decisórios que ocasionaram tais mudanças. Como embasamento teórico, além dos conteúdos das aulas, foram postados na Plataforma textos complementares com a finalidade de subsidiar os alunos no desenvolvimento da tarefa proposta. Ao final, 73 tarefas foram enviadas, através do recurso de Modalidade Avançada de Carregamento de Arquivos.

No Módulo III, em virtude da proximidade da Avaliação Presencial, foi trabalhado apenas os conteúdos das aulas 07 e 08 , já que pensou-se em deixar um espaço reservado via Plataforma, para que os alunos postassem suas dúvidas e questionamentos acerca de algum tema que não tinha ficado totalmente esclarecido. Como temas das referidas aulas, destacou-se: a política de financiamento da educação no Brasil e as políticas de formação docente e a regulação da profissão. Nessas aulas, procurou-se analisar as implicações das políticas de financiamento da educação na 
organização e gestão da educação brasileira e a compreensão do trabalho docente como profissão, analisando as políticas de formação e regulação. Como texto complementar foi postado um texto intitulado: Exclusão Includente e Inclusão Excludente. A atividade proposta à turma constou de dois momentos: no primeiro, pediu-se que fosse elencado os elementos positivos e negativos da autonomia financeira das escolas públicas, e no segundo, visitar o site do FNDE, na área destinada ao Programa Dinheiro Direto na Escola - PDDE (http://www.fnde.gov.br/programas/dinheirodireto-escola/dinheiro-direto-escola-apresentacao), e lá, coletar e analisar informações sobre o referido programa e responder a seguinte questionamento: o PDDE é um programa que contribui para a melhoria da gestão e financiamento da escola? O total de tarefas postadas para essa atividade chegou a 71, mantendo a média de postagem das outras avaliações.

Antes de iniciar o Módulo IV, foi reservado um período de revisão compreendido entre 29/04 a 02/05, já que dia 03 de maio iria ser realizada em cada polo de apoio presencial, a avaliação de aprendizagem presencial (AAP). Para isso, foram abertos 04 fóruns intitulados de fóruns de revisão, englobando os assuntos tratados nas aulas 02 a 08 . O curioso, é que nenhum aluno postou algum comentário sobre os temas tratados, nem sinalizou que estava com alguma dúvida, fato esse que iria repercutir negativamente ao final da disciplina, quando boa parte dos educandos não conseguiu ser aprovado por média, sendo submetidos a uma avaliação de recuperação.

O passo seguinte foi iniciar o Módulo IV e abordar as aulas 9, 10, 11 e 12, destacando-se os temas: a gestão da educação: principais conceitos e desafios (aula 9); os conselhos como instrumentos de democratização da gestão da educação (aula 10); Projeto Político-Pedagógico da Escola: importância e processos (aula 11) e Currículo escolar: concepções e organização (aula 12). Como objetivos propostos, procurou-se analisar os principais conceitos e desafios da gestão educacional; compreender o funcionamento e a importância dos conselhos na gestão da educação; conhecer e analisar a importância e processos de realização do Projeto Político-Pedagógico na gestão educacional e analisar as principais concepções e formas de organização do currículo escolar. Para subsidiar as discussões, foi postado o texto complementar: o sentido de qualidade na educação e como atividades avaliativas, foram utilizados 02 instrumentos. No primeiro, foi pedido que os educandos visitassem uma escola estadual (na ausência desta, poderia ser uma municipal), e colhessem dados referentes a atuação do conselho escolar na referida instituição, indagando sobre o papel do conselho, a periodicidade das reuniões e a amplitude de atuação do conselho na resolução de problemas inerentes à gestão de um modo geral da instituição. O resultado dessa visita foi postado na Plataforma em forma de relatório, perfazendo um total de 58 atividades avaliativas. Para as aulas 11 e 12, foi aberto um fórum avaliativo constando do seguinte questionamento: Existe relação entre Currículo Escolar e Projeto Político-Pedagógico? Em caso afirmativo, como se dá essa relação? Para essa avaliação, houve 65 participações, com diversos comentários, desde os mais simples aos mais complexos.

No quinto e último Módulo, foram debatidos assuntos concernentes as aulas 13, 14 e 15, sob os temas: a política de Educação Inclusiva e a Educação Indígena (aula 13); a participação cidadã na escola: eleições para dirigentes escolares e a família na escola (aula 14); os movimentos sociais na escola: sindicalização dos profissionais da educação e a atuação dos grêmios estudantis (aula 15). Nessas aulas, foram comentados assuntos referentes à legislação e as principais formas de realização da educação inclusiva e da educação indígena na educação básica; as formas e finalidades da participação cidadã na escola, por meio das eleições de dirigentes escolares e atuação das famílias e a importância da organização dos grêmios estudantis e sindicatos dos 
profissionais da educação no âmbito escolar. A avaliação foi realizada por meio de um questionário avaliativo contendo 10 perguntas com 04 alternativas de múltipla escolha, havendo um resultado satisfatório com 63 participações, no entanto, com um quantitativo de 24 alunos que ficaram com a nota abaixo da média (60).

Finalizando as atividades na Plataforma, foi disponibilizado uma aba contendo vários fóruns de perguntas, relacionados às aulas 09 a 15, as quais seriam objeto da avaliação final. Diferente do fórum de revisão das aulas 02 a 08 que não houve participações, nesses, foram postadas algumas perguntas/comentários (08 ao todo) através de um número reduzido de alunos - (03 no total). Através desses fóruns, finalizou-se os trabalhos pedagógicos no Ambiente Virtual de Aprendizagem, seguindo-se à Avaliação Final que ocorreu no dia 31 de maio em cada polo de apoio presencial.

Ao todo foram realizadas seis atividades avaliativas a distância, cada uma valendo 100 pontos, equivalendo a $40 \%$ da nota total da disciplina; os outros $60 \%$, foram obtidos através da avaliação presencial. Ao final, foi constatado que apenas 36 alunos conseguiram atingir a média da disciplina, que equivalia a 60 pontos, de acordo com as avaliações a distância e a prova presencial. Os resultados estão explicitados no Quadro 02 a seguir:

Quadro 02 - Quantitativos de alunos aprovados por média em cada Polo

\begin{tabular}{|c|c|}
\hline POLO DE APOIO PRESENCIAL & QUANTITATIVO DE ALUNOS APROVADOS POR MÉDIA \\
\hline Caraúbas & 10 \\
\hline Currais Novos & 03 \\
\hline Grossos & 06 \\
\hline Marcelino Vieira & 05 \\
\hline Natal & 09 \\
\hline Parnamirim & 01 \\
\hline São Gonçalo do Amarante & 02 \\
\hline TOTAL & 36 \\
\hline
\end{tabular}

Fonte: Elaboração do autor, a partir de informações de: http://ead.ifrn.edu.br/moodle

Outro ponto observado, foi em relação ao número de alunos que não participaram de todas as avaliações propostas, ocasionando em uma reprovação imediata sem direito à recuperação, já que obtiveram notas igual ou abaixo de 20 pontos, como se verifica em seguida:

Quadro 03 - Quantidade de alunos reprovados sem direito à recuperação com notas igual ou inferior a 20 pontos em cada Polo

\begin{tabular}{|c|c|}
\hline POLO DE APOIO PRESENCIAL & ALUNOS REPROVADOS \\
\hline Caraúbas & - \\
\hline Currais Novos & - \\
\hline Grossos & - \\
\hline Marcelino Vieira & 02 \\
\hline Natal & 05 \\
\hline Parnamirim & 01 \\
\hline São Gonçalo do Amarante & 09 \\
\hline TOTAL &
\end{tabular}

Fonte: Elaboração do autor, a partir de informações de: http://ead.ifrn.edu.br/moodle

Mas, o que chamou mais a atenção, foi o grande número de alunos que estavam matriculados, mas não participaram sequer de alguma atividade proposta. Como não se sabe ao certo o motivo da não participação, neste trabalho os tais serão considerados como evadidos ou desistentes, conforme informações abaixo: 
Quadro 04 - Quantidade de alunos evadidos/desistentes em cada Polo

\begin{tabular}{|c|c|}
\hline POLO DE APOIO PRESENCIAL & ALUNOS EVADIDOS/DESISTENTES \\
\hline Caraúbas & 08 \\
\hline Currais Novos & 04 \\
\hline Grossos & 11 \\
\hline Marcelino Vieira & 04 \\
\hline Natal & 09 \\
\hline Parnamirim & 16 \\
\hline São Gonçalo do Amarante & 03 \\
\hline TOTAL & 55 \\
\hline
\end{tabular}

Fonte: Elaboração do autor, a partir de informações de: http://ead.ifrn.edu.br/moodle

Essa quantidade expressiva de desistentes/evadidos, merece ser objeto de estudos posteriores, a fim de identificar os motivos de tão alto índice evasivo e procurar alternativas viáveis de combate à evasão na educação a distância.

Por fim, é apresentada a situação daqueles que foram submetidos a uma Prova Final, uma espécie de "recuperação" aos que não atingiram a média no processo normal, constando os aprovados e reprovados.

Quadro 05 - Quantidade de alunos aprovados e reprovados na Prova Final

\begin{tabular}{|c|c|c|c|}
\hline POLO & ALUNOS & APROVADOS & REPROVADOS \\
\hline Caraúbas & 10 & 10 & - \\
\hline Currais Novos & 09 & 08 & 01 \\
\hline Grossos & 01 & 01 & - \\
\hline Marcelino Vieira & 14 & 13 & 01 \\
\hline Natal & 04 & 04 & 01 \\
\hline Parnamirim & 09 & 08 & 01 \\
\hline São G. do Amarante & 03 & 02 & 04 \\
\hline TOTAL & 50 & 46 & . \\
\hline
\end{tabular}

Fonte: Elaboração do autor, a partir de informações de: http://ead.ifrn.edu.br/moodle

Ao término da Prova Final, pôde-se perceber um resultado satisfatório, já que $92 \%$ dos alunos que foram submetidos à referida prova, conseguiram o resultado positivo. Somando-se os 46 aprovados na prova final, aos 36 aprovados por média na primeira fase, obteve-se um resultado de 82 alunos aprovados, dos 86 que estavam frequentando à Plataforma Virtual e participaram de todas as avalições. $O$ resultado final é exposto com mais detalhes na tabela a seguir:

Quadro 06 - Resultado Final

\begin{tabular}{|c|c|c|c|c|}
\hline POLO & $\begin{array}{c}\text { ALUNOS } \\
\text { APROVADOS POR } \\
\text { MÉDIA }\end{array}$ & $\begin{array}{c}\text { ALUNOS } \\
\text { APROVADOS NA } \\
\text { PROVA FINAL }\end{array}$ & $\begin{array}{c}\text { REPROVADOS NA } \\
\text { PROVA FINAL }\end{array}$ & $\begin{array}{c}\text { TOTAL DE } \\
\text { APROVAÇÃO }\end{array}$ \\
\hline Caraúbas & 10 & 10 & - & 20 \\
\hline Currais Novos & 03 & 08 & - & 11 \\
\hline Grossos & 06 & 01 & 01 & 07 \\
\hline Marcelino Vieira & 05 & 13 & - & 18 \\
\hline Natal & 09 & 04 & 01 & 01 \\
\hline Parnamirim & 01 & 08 & 04 & 04 \\
\hline São G. do Amarante & 02 & 02 & 04 & 82 \\
\hline TOTAL & 36 & 46 & & \\
\hline
\end{tabular}

Fonte: Elaboração do autor, a partir de informações de: http://ead.ifrn.edu.br/moodle 


\section{CONCLUSÃO}

Neste sentido, a experiência docente junto à turma do 50 período do Curso de Licenciatura em Letras Espanhol do IFRN - Campus Central, na disciplina Organização e Gestão da Educação Brasileira, proporcionou compreender como ocorre o fluxo das atividades pedagógicas em uma turma de Licenciatura na modalidade a distância, mediado pelas Novas Tecnologias da Informação e da Comunicação - NTIC's, utilizando como ambiente virtual, o Moodle. Ela veio também contribuir no sentido de se refletir de maneira mais cuidadosa e criteriosa, acerca do alto índice de evasão escolar ainda presente nessa modalidade.

Por fim, apesar dessas vicissitudes, percebeu-se como essa modalidade de ensino é importante à difusão da educação nos mais longínquos espaços, viabilizando saberes significativos à formação discente, contribuindo dessa forma, para os percursos formativos entre educandos, professores e tutores. Sendo assim, espera-se que este trabalho sirva como norteador e contribua para o entendimento das dificuldades, desafios e possíveis rumos a serem traçados na EaD no curso de Licenciatura em Letras Espanhol do IFRN.

\section{REFERÊNCIAS}

1. BRASIL. [Lei Darcy Ribeiro (1996)]. LDB: Lei de diretrizes e bases da educação nacional [recurso eletrônico]: Lei no 9.394, de 20 de dezembro de 1996, que estabelece as diretrizes e bases da educação nacional. - 9. ed. - Brasília: Câmara dos Deputados, Edições Câmara, 2014. Disponível em: <http://www.sineperj.org.br/admIN/upload/legislacao_has_arquivo/LDBatua lizadaemmaio 2014.pdf> Acesso em: 05 mai. 2015.

2.

Decreto no 5.622, de 19 de dezembro de 2005 (Regulamenta o art. 80 da Lei no 9.394, de 20 de dezembro de 1996, que estabelece as diretrizes e bases da educação nacional. Disponível em: <http://portal.mec.gov.br/seed/arquivos/pdf/dec_5622.pdf> Acesso: 05 mai. 2015.

3. Decreto no 5.800, de 08 de junho de 2006 (Dispõe sobre o Sistema Universidade Aberta do Brasil - UAB. Disponível em: http://www.uab.capes.gov.br/images/stories/down loads/legislacao/decreto5800.pdf Acesso em: 05 mai. 2015.

4. CORDEIRO, Jaime. Didática. 1. ed. São Paulo: Contexto, 2009.

5. HERMIDA, Jorge Fernando; BONFIM, Cláudia Ramos de Souza. A educação à distância: história, concepções e perspectivas. Revista HISTEDBR On-line, Campinas, n. especial, p.166-181, ago 2006. Disponível em: http://www.histedbr.fe.unicamp.br/revista/edicoes/22e/art11_22e.pdf acesso em: 06 maio 2015.

6. IFRN. Histórico do Campus EaD. Disponível em: <http://portal.ead.ifrn.edu.br/sobre-ocampus-ead/historico> Acesso em: 27 jul. 2014.

7. _. Projeto Pedagógico do Curso Superior de Licenciatura em Letras Espanhol na modalidade a distância. Disponível em: <http://portal.ead.ifrn.edu.br/wpcontent/uploads/Documentos/PPP/letras_espanhol.pdf> Acesso em: 29 jul. 2014.

8. KENSKI, Vani Moreira. Novos processos de interação e comunicação no ensino mediado pelas tecnologias. São Paulo: Cadernos de Pedagogia Universitária (USP), 2008.

9. . O Papel do Professor da Sociedade Digital. In: CASTRO, Amélia Domingues de; 
CARVALHO, Anna Maria Pessoa de (Orgs.). Ensinar a Ensinar. São Paulo: Cengage Learning, 2012.

10. LIBÂNEO, José Carlos. Didática: Série formação do professor, coleção magistério - 2o grau. 1 . ed. São Paulo: Cortez, 1994.

11. LUCKESI, Cipriano Carlos. Avaliação da aprendizagem escolar. 7. ed. São Paulo: Cortez, 1998.

12. PALLOFF, Rena; PRATT, Keith. Construindo Comunidades de Aprendizagem no Ciberespaço. Porto Alegre: Artmed, 2002.

13. TIBA, Içami. Pais e educadores de alta performance. São Paulo, Integrante Editora, 2012

14. VASCONCELOS, Celso dos Santos. Coordenação do Trabalho Pedagógico: do projeto políticopedagógico ao cotidiano da sala de aula. 6. ed. São Paulo: Libertad Editora, 2006. 